Published in final edited form as:

Schizophr Res. 2007 January ; 89(1-3): 72-85. doi:10.1016/j.schres.2006.09.002.

\title{
Minor physical anomalies in schizophrenia: a meta-analysis
}

\author{
Seth M. Weinberg ${ }^{a, b}$, Elizabeth A. Jenkins ${ }^{c}$, Mary L. Marazita ${ }^{a, c}, d, e$, and Brion S. Mahera \\ aCenter for Craniofacial and Dental Genetics, Department of Oral Biology, School of Dental Medicine, \\ University of Pittsburgh, Pittsburgh, PA 15219, USA \\ bDepartment of Anthropology, University of Pittsburgh, Pittsburgh, PA 15260, USA \\ cDepartment of Human Genetics, Graduate School of Public Health, University of Pittsburgh, Pittsburgh, \\ PA 15261, USA \\ dDepartment of Oral and Maxillofacial Surgery, School of Dental Medicine, University of Pittsburgh, \\ Pittsburgh, PA 15261, USA \\ eDepartment of Psychiatry, School of Medicine, University of Pittsburgh, Pittsburgh, PA 15261, USA
}

\section{Abstract}

Numerous studies report an increased frequency of minor physical anomalies (MPAs) in schizophrenic individuals compared with controls. However, these studies vary considerably regarding the magnitude of the case-control disparity and the topographical distribution of the anomalies. A meta-analysis was carried out on the existing MPA literature in an effort to better understand the relationship between MPAs and schizophrenia. Following a literature search, 13 studies were identified that met our inclusion criteria. Mean total MPA scores were available for 11 of these studies, whereas only seven studies provided regional MPA scores. For both the total MPA and regional MPA analyses, pooled effect sizes (Hedges' $g$ and pooled odds ratios, respectively) were calculated along with tests of heterogeneity. For the total MPA analyses, a meta-regression approach was used to explore the relationship between possible moderator variables (e.g., number of MPA scale items) and effect size heterogeneity. The magnitude of the pooled effect size for the total MPA scores was high $(1.131 ; \mathrm{p}<0.001)$, indicating significantly more overall MPAs in schizophrenic individuals. Significant effect size heterogeneity was present $(\mathrm{p}<0.001)$; however, this heterogeneity could not be explained by any of the included moderator variables. The regional MPA analysis revealed significantly increased MPAs in all six anatomical regions $(\mathrm{p}<0.05)$, although the pooled odds ratios for these regions did not differ significantly from one another. These results suggest a lack of regional specificity for MPAs in schizophrenia.

\section{Keywords}

Minor physical anomalies; Schizophrenia; Meta-Analysis

Corresponding Author: Seth M. Weinberg, 100 Technology Drive, Suite 500, Pittsburgh, PA 15219, USA, Tel: 1-412-648-9206, Fax: 1-412-648-8779, E-mail: smwst46@sdmgenetics.pitt.edu.

Publisher's Disclaimer: This is a PDF file of an unedited manuscript that has been accepted for publication. As a service to our customers we are providing this early version of the manuscript. The manuscript will undergo copyediting, typesetting, and review of the resulting proof before it is published in its final citable form. Please note that during the production process errors may be discovered which could affect the content, and all legal disclaimers that apply to the journal pertain. 


\section{Introduction}

The neurodevelopmental model of schizophrenia asserts that the etiological origins of the disease can be traced to events occurring prenatally (Weinberger, 1987; Murray et al., 1992; Waddington et al., 1999; Marenco and Weinberger, 2000; McGrath et al., 2003). Several diverse lines of evidence now support this model including epidemiological data (e.g., in utero disease and stress exposure [reviewed in Cannon et al., 2004]), the presence of birth/pregnancy complications (Geddes and Lawrie, 1995; NcNeil et al., 2000; Cannon et al., 2002), the observed pattern of developmental brain anomalies (Roberts et al., 1987; Weinberger, 1987; Woods, 1998; Harrison, 1999), the presence of pre-morbid behavioral and neuromotor deficits (Davies et al., 1998; Kravariti et al., 2004), and the gross somatic abnormalities that tend to accompany the disease (Murphy and Owen, 1996; Buckley, 1998; NcNeil et al., 2000). Regarding this last category, particular emphasis has been placed on the presence of excess minor physical anomalies (MPAs) in those affected with schizophrenia. MPAs are typically described as subtle morphological deviations that are of little functional or cosmetic consequence (Jones, 1997), but may represent risk markers for underlying disease susceptibility (Hoyme, 1993; Tarrant and Jones, 1999); this is thought to be particularly true when multiple MPAs occur together in a given individual and/or when an individual is already at high risk (e.g., the first degree relative of an affected individual).

In the vast majority of studies, the Waldrop scale (or some variant thereof) has been used to assess MPAs in schizophrenia (Waldrop et al., 1968; Waldrop and Halverson, 1971). At best, this scale is a heterogeneous suite of physical features that span a wide range of developmental time points and vary considerably in their etiological relevance. It is not surprising, therefore, that its widespread implementation has drawn some pointed criticism (Krouse and Kauffman, 1982; Murphy and Owen, 1996; Lane et al., 1997; Trixler et al., 1997; 2001; McNeil and Cantor-Graae, 2000). From an embryological perspective, however, many of the items on the Waldrop scale (specifically craniofacial features) are closely related to underlying brain development due to shared ectodermal origins and/or functional growth dependencies (Le Douarin and Kalcheim, 1999; Francis-West et al., 2003). This fact legitimizes to some extent the use of this admittedly imperfect tool in psychiatric research.

Numerous studies to date have examined the relationship between MPAs and schizophrenia (Murphy and Owen, 1996). These studies typically fall into one of the following two categories: those that compare the frequency of MPAs between schizophrenic or at-risk cases and healthy controls and those that explore the relationship between MPAs and other putative indices (morphological, cognitive, etc.) within a sample of schizophrenic individuals. Regarding studies that fall into the first category, there is general agreement that schizophrenic cases possess more MPAs than healthy controls. It is also clear, however, that the magnitude of the disparity in MPA scores between cases and controls varies widely across studies. Currently, there is no clear explanation for this outcome variability. Furthermore, results of studies reporting the topographical distribution of MPAs in schizophrenic individuals are highly variable, although it is generally held that the greatest number of MPAs occur within the oral cavity (Tarrant and Jones, 1999). Importantly, information about which regions are most susceptible to MPAs can provide clues to the temporal origins of the dysmorphology and its underlying relationship to brain development.

Thus, there are still a number of issues to be clarified concerning the link between MPAs and schizophrenia. In this report, we utilize a meta-analytic approach to synthesize the existing evidence on MPAs and schizophrenia. In doing so, we attempt to answer the following questions: 1) Do schizophrenic individuals consistently demonstrate more MPAs than healthy controls? 2) Can certain methodological factors adequately account for the variability in 
casecontrol differences across studies? 3) Do the case-control differences in MPAs occur more often in specific anatomical regions?

\section{Materials and Methods}

\subsection{Literature search and selection}

To identify pertinent articles, a two-stage literature search was carried out. First, an online PubMed database search was performed. Search terms included "minor physical anomalies and schizophrenia", "MPA and schizophrenia" and "dysmorphic and schizophrenia." The PubMed search was limited to non-review articles in English. This search produced 76 unique articles, 45 of which were deemed relevant after review of titles and abstracts. In the next phase, the references from each relevant study were examined manually to identify any studies overlooked in the initial PubMed search; four were found. As a result, a total of 49 relevant articles were identified. Of these, only 13 studies met our inclusion criteria, namely that: 1) a case-control design was utilized; 2) mean MPA scores and/or raw MPA frequencies were available for both the case and control group; 3) cases had a diagnosis of schizophrenia, not schizoaffective or schizotypal disorder; 4) established and internationally recognized diagnostic criteria (e.g., DSM) were used; 5) the Waldrop scale or some variant of it was used in the MPA assessment; and 6) the samples did not overlap with those reported in other studies. In situations were there was uncertainty regarding sample overlap among studies, only one study was chosen to be included. The decision over which study to include was made on a case by case basis but was typically informed by factors such as sample size and overall study quality. Studies based on samples of twins were also excluded because offspring that share a prenatal environment may be developmentally compromised, which could obscure any casecontrol differences. Descriptive characteristics of the 13 included studies are provided in Table 1. A list of the 36 excluded studies and the reason(s) for their exclusion are provided in Table 2.

\subsection{Statistical analysis}

2.2.1. Assessment of Total MPA Scores-Of the 13 studies that met our inclusion criteria, 11 provided mean scores for the total set of MPAs in both schizophrenia cases and healthy controls (Gualtieri et al., 1982; Lal and Sharma, 1987; Green et al., 1989; Lohr and Flynn, 1993; Alexander, 1994; Lane et al., 1997; Ismail et al., 1998; Hata et al., 2003a; Sivkov and Akebaliev, 2003; Gourion et al., 2004a; Joo et al., 2005). For each study, the effect size $g$ (Hedges' $g$ ) was calculated. Hedges' $g$ is an unbiased parametric effect size index based on the standardized mean difference between two samples. As such, it can be calculated directly from the case and control means, standard deviations and sample sizes provided (Hedges and Olkin, 1985). Typically, effect size magnitudes between 0.2 and 0.5 are interpreted as weak, between 0.5 and 0.8 as moderate, and over 0.8 as large (Cohen, 1988). To test whether a given effect size is significantly different from zero (i.e., no difference between groups), $95 \%$ confidence intervals were generated (Klein, 2004; p. 108). Once the effect size for each individual study was obtained, the variance across effect sizes was assessed by calculating Cochran's heterogeneity statistic Q (Cochran, 1954). This statistic tests the null hypothesis that the effect sizes obtained from a sample of independent studies are similar enough to estimate a common population effect size.

Finally, a single pooled effect size for all 11 studies was calculated accompanied by its $95 \%$ confidence interval, with each study weighted by its conditional variance (inverse variance method). Fixed-effects models for estimating cumulative effect sizes are considered inappropriate in most circumstances when a large amount of heterogeneity is present (DerSimonian and Laird, 1986). In these situations, a random-effects model is typically utilized where a second weighting term is included to account for the between-study variation in effect 
size (Sutton et al., 2000; p. 75). The results of the abovementioned heterogeneity test informed our choice of model. To evaluate potential publication bias (e.g., the non-publication of studies with negative findings), Rosenthal's fail-safe N statistic was computed (Rosenthal, 1979). This statistic provides an estimate of how many additional studies with a zero effect size would hypothetically be required to render a given pooled effect size statistically non-significant.

Following the initial meta-analysis, a sensitivity analysis was performed. In this analysis, each of the 11 original studies was excluded one at a time and the pooled effect sizes were recalculated from the remaining ten studies in an iterative fashion. This allowed for an assessment of the overall robustness of the meta-analysis as well as detection of the most influential studies. In addition, meta-regression was utilized to explore the extent to which selected study characteristics might explain between-study variation in effect size. A mixedeffects regression model (method of moments) was employed, where a random effect term is included in the regression model to account for any residual variance left unexplained by the included covariate (Sutton et al., 2000). At a practical level, the mixed-effects model produces wider confidence intervals for the regression parameters, compared to the standard fixedeffects model (Thompson and Sharp, 1999). To evaluate the explanatory power of each covariate (i.e., study characteristic) in the regression model, tau-squared $\left(\tau^{2}\right)$, which is an estimate of the residual between-study variance in effect size, was generated both before and after covariate inclusion. The degree of reduction in $\tau^{2}$ following covariate inclusion provides a means of assessing how much variance was accounted for by that covariate. Specifically, we predict that number of MPA scale items, overall methodological quality, and case-control sex ratio will account for a significant portion of the effect size variance. To assess methodological quality, a single score was derived for each study based on a ten item quality scale (Table 3); studies with higher scores were deemed superior. The case-control sex ratio was determined for each study by dividing the male to female ratio in the case sample by the male to female ratio in the control sample. Values equal to one indicate that the proportion of males (relative to females) in the case and control samples are equivalent. Values greater than or less than one indicate that the proportion of males (relative to females) in the case sample is either greater than or less than that in the control sample, respectively. These values can be calculated directly from the information in Table 1.

2.2.2. Regional MPA Analysis-A separate analysis of MPA frequency by anatomical region (head, eyes, ears, mouth, hands and feet) was carried out. For this analysis, a total of seven studies could be included (Green et al., 1989; McGrath et al., 1995; Ismail et al., 1998; Lawrie et al., 2001; Hata et al., 2003a; Sivkov and Akebaliev, 2003; Gourion et al., 2004a) because they were the only studies that provided raw counts for MPAs. Per region odds ratios (ORs) were calculated for each study in the following manner:

$$
O R=a d / b c
$$

where $a$ and $c$ are the total number of anomalies observed per region for cases and controls, respectively, and $b$ and $d$ are the total number of anomalies absent per region for cases and controls, respectively. The quantities for $b$ and $d$ were computed by taking the maximum number of anomalies possible for a particular region (the case/control sample size multiplied by the number of items included for that region) and subtracting the actual number of anomalies observed, quantities $a$ and $c$. For example, let us suppose that for a given study with a sample of 30 cases and 40 controls, five anomalies were evaluated for the head region. The maximum number of head anomalies possible in this scenario would be 150 for cases and 200 for controls.

For each region, the ORs from each study were combined using the Mantel-Haenszel method with continuity correction for empty cells (Sutton et al., 2000; p. 64). As with the analysis of 
total MPA scores, approximate $95 \%$ confidence intervals and heterogeneity statistics were computed to aid interpretation of the per region pooled OR. Once pooled ORs were derived for each region, a mixed-model ANOVA was used to compare the pooled estimates across regions. The purpose of this test was to determine whether the prevalence of MPAs in schizophrenia was significantly greater in particular regions. Due to the small number of studies included, it was not feasible to utilize meta-regression to explore the relationship between individual study characteristics and ORs.

All calculations and statistical tests were carried out with the software package Comprehensive Meta-Analysis version 2.0 (Biostat Inc., Englewood, NJ).

\section{Results}

\subsection{Mean total MPA scores}

Meta-analysis results along with descriptive statistics are reported in Table 4 and represented graphically in Figure 1. Individual effect size statistics for the 11 studies ranged from 0.31 to 2.06 , with seven studies reporting effect sizes over 0.80 . In all 11 studies, the direction for the effect size indicates that schizophrenic cases possessed higher MPA scores than controls. In only a single study (Alexander et al., 1994), the effect size failed to reach statistical significance. Given the range of individual effect sizes observed, there was significant effect size heterogeneity across studies $(\mathrm{Q}=128.33$; $\mathrm{df}=10 ; \mathrm{p}<0.001)$. In light of this fact, a randomeffects model was used to generate a pooled effect size estimate for the 11 studies. The magnitude of the pooled effect size for this sample of studies was quite large at $1.131 \mathrm{p}<$ 0.001), indicating a considerable disparity in total MPA scores between schizophrenic cases and healthy controls. The fail-safe $\mathrm{N}$ statistic indicated that over 1000 studies with null effect sizes would be needed to render this pooled estimate insignificant, suggesting that publication bias played a little or no role in producing the observed results.

Results of the sensitivity analysis revealed that removing any single study failed to result in a significant shift in the pooled effect size estimate (see Figure 2). The largest negative shift occurred following the removal of Lal and Sharma (1987), which was to be expected, based on the large effect size observed for this study (2.06). The largest positive shift occurred following the removal of Joo et al. (2005). In both cases, however, there was still a negligible net effect on the overall pooled estimate. This suggests that all 11 studies were similarly influential and that the meta-analysis is generally robust. Furthermore, these results provide indirect evidence that certain moderator variables were poorly correlated with effect size. For instance, in seven of the 11 studies the samples were derived from different populations (the other four were from the USA; see Table 1). Since the removal of any one of these studies produced almost no shift in the pooled effect size, population was unlikely to be a major determining factor of study outcome. In other words, the variation in effect size across studies could not be adequately explained by the population from which the study samples were derived.

As mentioned previously, a more formal evaluation of effect size heterogeneity was also carried out using a meta-regression approach, where the relationship between quantitative study characteristics and effect size was explored. Neither number of MPA scale items nor overall methodological quality nor case-control sex ratio was able to account for a significant proportion of the between-study variance in effect size. Prior to the inclusion of these covariates, between-study variance $\left(\tau^{2}\right)$ was 0.353 . Following their inclusion, the residual between-study variance was 0.232 for number of MPA items, 0.224 for methodological quality and 0.249 for case-control sex ratio (a 33\%, 37\% and 29\% shift, respectively). This indicates that only a modest portion of the original effect size variance could be explained by any one covariate. Not surprisingly, none of the regression models were statistically significant ( $p$ > 
0.05). Additionally, no meaningful trend could be detected between year of publication and effect size, as revealed visually in Figure 1. Consequently, because the criteria used for schizophrenia diagnosis (DSM-III, DSM-III-R, DSM-IV) has evolved over the time frame of these publications, this can be precluded as a factor underlying effect size heterogeneity as well.

\subsection{Regional MPA analysis}

Individual study and pooled results for the regional MPA analysis are reported in Table 5 as odds ratios and represented visually in Figure 3. In all regions the vast majority of individual study ORs were greater than one, indicating an increased frequency of MPAs in schizophrenia; in just over half (54\%) of these cases the OR was statistically significant. Three studies reported ORs less than one: Green et al. (1989) for eyes, McGrath et al. (1995) for ears and mouth and Lawrie et al. (2001) for ears, mouth and hands. However, none of these ORs were significantly different from one. An OR for the head region for McGrath et al. (1995) could not be calculated because the authors did not include any anomalies from this region in their analysis. Each of the six anatomical regions (head, eyes, ears, mouth, hands, and feet) had a pooled effect size significantly greater than one $(\mathrm{p}<0.05)$. In terms of specific regions, the mouth region was found to have the largest pooled effect size of 2.65 as well as the greatest confidence interval, while the ears were found have the smallest pooled effect size of 1.42 with the smallest confidence interval (see Figure 3). Despite this variability, the pooled ORs across the six regions did not differ significantly from one another, as determined by ANOVA $(\mathrm{Q}=8.359$; $\mathrm{df}=5 ; \mathrm{p}=0.14$ ). All regions except head were found to have significant within-region heterogeneity.

\section{Discussion}

The results of the present meta-analysis indicate that mean total MPA scores derived using the Waldrop scale are substantially different between schizophrenic individuals and healthy controls. In each of the 11 studies where mean total MPA scores were available, the schizophrenic sample was observed to have more MPAs than controls. In most cases the magnitude of the case-control difference was quite large; effect sizes in excess of 0.80 were observed in seven studies. Moreover, the pooled effect size calculated from all 11 studies was $1.131(0.762-1.501 ; \mathrm{p}<0.001)$, which represents the single best point estimate of case-control disparity. The robustness of this pooled estimate was confirmed through sensitivity analysis, where it was observed that dropping any single study from the meta-analysis had a negligible impact on the cumulative effect size (Figure 2). These results are in agreement with the broader MPA literature and provide additional support that MPAs (assessed as total scores) can serve as a reliable and powerful discriminator between schizophrenic cases and controls.

Despite this fact, a high degree of variability in effect size magnitude was observed among these 11 studies. One of the stated goals of the meta-analysis was to identify potential factors that moderate this effect size variability. In particular, it was predicted that the number of MPA scale items, overall methodological quality, and the proportion of males to females in the case versus control sample would each account for a significant portion of the between-study variation in effect size. Separate mixed-effects meta-regression analyses indicated, however, that none of these moderator variables were able to account for a substantial portion of the observed effect size variance. These results may help clarify some unresolved issues within the MPA and schizophrenia literature. For example, regarding number of MPA items, a handful of recent studies have used expanded versions of the original Waldrop scale (Ismail et al., 1998; Gourion et al. 2003; 2004a). There is some uncertainty, however, as to the importance of these additional items, both in terms of etiological significance and discriminatory ability. The apparent lack of relationship between number of MPA items and effect size observed here 
suggests that the presence of these additional items may not aid substantially in discriminating cases from controls. Interestingly, these results are supported largely by the findings of both Ismail et al. (1998) and Gourion et al. (2004a), who reported that among MPAs that significantly differentiated cases from controls, the majority were derived from the original Waldrop scale. In light of these findings, it may be worthwhile to reconsider whether an expanded MPA scale is necessary.

Regarding case-control sex ratio, previous studies have reported either excess MPAs in male schizophrenics (Marcus et al., 1985; Akabaliev and Sivkov, 2003; Sivkov and Akabaliev, 2004), excess MPAs in female schizophrenics (Green et al., 1989; 1994b; Lal and Sharma, 1987) or no sex differences in MPA frequency (Cantor-Graae et al., 1994; McGrath et al., 1995; Akabaliev and Sivkov, 1998; Gourion et al., 2004a; 2004b; Joo et al., 2005). The present meta-analysis results fail to support the contention that the gender composition of the case or control group relates to the magnitude of the observed case-control difference in total MPA score. This implies that the gender-balanced samples may be unnecessary in case-control studies of MPA frequency in schizophrenia. Although specific tests were not performed, our results also suggest that year of publication, trends in diagnostic criteria and geographical origin of the sample played little role in the case-control outcome. It should be kept in mind, however, that these results only pertain to outcomes involving mean total MPA score; for scores derived from specific regions and/or individual MPAs, any or all of these factors may still prove to be relevant.

Numerous studies report a disproportionately high number of MPAs in the craniofacial complex of schizophrenic individuals (Green et al., 1994a; Lane et al., 1997; Akabaliev and Sivkov, 1998; Akabaliev et al., 2001; Lawrie et al., 2001; Trixler et al., 2001; Elizarrarás-Rivas et al., 2003; Hata et al., 2003a; Gourion et al., 2004a). Anomalies of the mouth region (e.g., palatal anomalies) are often reported to be particularly prevalent (Green et al., 1989; McGrath et al., 1994; Lane et al., 1997; Ismail et al., 1998; Hata et al., 2003a; Gourion et al., 2004a). The results of our regional MPA analysis provide only limited support for these claims. Considering the pooled ORs by region, all regions had a pooled OR significantly greater than one indicating excess anomalies in schizophrenic individuals compared to controls. Furthermore, the mouth region did have the highest OR, followed closely by the head, eye, foot, hand and ear region in decreasing order (Table 5). Nevertheless, these pooled ORs did not differ significantly across regions $(p=0.14)$, suggesting that these six anatomical regions are roughly equivalent in their susceptibility to MPAs. Moreover, there was great deal of heterogeneity in ORs across studies for each region, the mouth region demonstrating the greatest variability with two studies even showing a trend towards increased MPAs in controls rather than cases.

A major limitation of the present meta-analysis was the small sample of studies that met our inclusion criteria. This fact particularly impacts the statistical assessment of moderator variables on effect size variability where regression methods are employed. Consequently, the absence of a significant relationship between effect size and any of the moderator variables considered here could have been impacted by a lack of statistical power, thus any conclusions based on these results should be tempered. There were also a number of potentially important moderator variables that could not be formally evaluated (e.g., age of onset, durations of illness) because the data were not available for enough studies. The fact the only seven studies could be included in the regional MPA analysis precluded carrying out a formal assessment of heterogeneity altogether. Unfortunately, it was also not plausible to consider individual MPAs due to the fact that too few studies provided the necessary raw data, thus our analysis was limited to total MPA scores and regional summary scores. Although the Waldrop scale is currently the most widely used tool to assess dysmorphology in schizophrenia, its low sensitivity and lack of construct validity make it problematic. To address some of these deficits, 
a handful of studies have begun to incorporate anthropometric methods in order to generate quantitative descriptions of the head and face in schizophrenic individuals (Lane et al., 1997, McGrath et al., 2002, Hennessey et al., 2004; Kelly et al., 2005). Although results to date have been inconsistent, this approach is likely to yield a wealth of information about the nature of dysmorphology in schizophrenia.

\section{Acknowledgments}

Support for Dr. Marazita and Dr. Maher was provided by NIH grants R01-DE016148 and P50-DE016215. The authors would like to thank Dr. Michael Vanyukov for his advice and support.

\section{References}

Akabaliev VH, Sivkov ST. Minor physical anomalies in schizophrenia. Folia Med. (Plovdiv) 1998;40 (2):39-45. [PubMed: 9707811]

Akabaliev VH, Sivkov ST. Sexual dimorphism in minor physical anomalies in schizophrenic patients and normal controls. Compr. Psychiatry 2003;44(4):341-348. [PubMed: 12923713]

Akabaliev VH, Sivkov ST, Baltadjiev GA. Discriminant analysis of minor physical anomalies as dysontogenetic markers of schizophrenia. Folia Med. (Plovdiv) 2001;43(3):21-26. [PubMed: 11930828]

Alexander RC, Mukherjee S, Richter J, Kaufmann CA. Minor physical anomalies in schizophrenia. J. Nerv. Ment. Dis 1994;182(11):639-644. [PubMed: 7964672]

Buckley PF. The clinical stigmata of aberrant neurodevelopment in schizophrenia. J. Nerv. Ment. Dis 1998;186(2):79-86. [PubMed: 9484307]

Buckley PF, Moore C, Long H, Larkin C, Thomson P, Mulvany F, Redmond O, Stack JP, Ennis JT, Waddington JL. 1H-magnetic resonance spectroscopy of the left temporal and frontal lobes in schizophrenia: clinical, neurodevelopmental, and cognitive correlates. Biol. Psychiatry 1994;36(12): 792-800. [PubMed: 7893844]

Cannon, M.; Dean, K.; Jones, PB. Early environmental risk factors for schizophrenia. In: Keshavan, MS.; Kennedy, JL.; Murray, RM., editors. Neurodevelopment and Schizophrenia. Cambridge: Cambridge University Press; 2004. p. 191-209.

Cannon M, Jones PB, Murray RM. Obstetric complications and schizophrenia: historical and metaanalytic review. Am. J. Psychiatry 2002;159(7):1080-1092. [PubMed: 12091183]

Cantor-Graae E, Ismail B, McNeil TF. Neonatal head circumference and related indices of disturbed fetal development in schizophrenic patients. Schizophr. Res 1998;32(3):191-199. [PubMed: 9720124]

Cantor-Graae E, McNeil TF, Torrey EF, Quinn P, Bowler A, Sjostrom K, Rawlings R. Link between pregnancy complications and minor physical anomalies in monozygotic twins discordant for schizophrenia. Am. J. Psychiatry 1994;151(8):1188-1193. [PubMed: 8037254]

Cochran WG. The combination of estimates from different experiments. Biometrics 1954;10(1):101129.

Cohen, J. Statistical Power Analysis for the Behavioral Sciences. Hillsdale: Lawrence Earlbaum Associates; 1988.

Davies N, Russell A, Jones P, Murray RM. Which characteristics of schizophrenia predate psychosis? J. Psychiatr. Res 1998;32(3-4):121-131. [PubMed: 9793865]

DerSimonian R, Laird N. Meta-analysis in clinical trials. Controlled Clin. Trials 1986;7(3):177-188. [PubMed: 3802833]

Edgar JC, Yeo RA, Gangestad SW, Blake MB, Davis JT, Lewine JD, Cañive JM. Reduced auditory M100 asymmetry in schizophrenia and dyslexia: applying a developmental instability approach to assess atypical brain asymmetry. Neuropsychologia 2005;44(2):289-299. [PubMed: 15992835]

Elizarraras-Rivas J, Fragoso-Herrera R, Cerdan-Sanchez LF, Ramos-Zepeda R, Barajas-Barajas LO, Troyo-Sanroman R. Minor physical anomalies and anthropometric measures in schizophrenia: a pilot study from Mexico. Schizophr. Res 2003;62(3):285-287. [PubMed: 12837527]

Francis-West PH, Robson L, Evans DJ. Craniofacial development: the tissue and molecular interactions that control development of the head. Adv. Anat. Embryol. Cell Biol 2003;169:1-138. 
Geddes JR, Lawrie SM. Obstetric events in schizophrenia: a meta-analysis. Br. J. Psychiatry 1995;167 (6):786-793. [PubMed: 8829748]

Gourion D, Goldberger C, Bourdel MC, Bayle FJ, Loo H, Krebs MO. Minor physical anomalies in patients with schizophrenia and their parents: prevalence and pattern of craniofacial abnormalities. Psychiatry Res 2004a;125(1):21-28. [PubMed: 14967549]

Gourion D, Goldberger C, Bourdel MC, Bayle FJ, Millet B, Olie JP, Krebs MO. Neurological soft-signs and minor physical anomalies in schizophrenia: differential transmission within families. Schizophr. Res 2003;63(1-2):181-187. [PubMed: 12892872]

Gourion D, Goldberger C, Olie JP, Loo H, Krebs MO. Neurological and morphological anomalies and the genetic liability to schizophrenia: a composite phenotype. Schizophr. Res 2004b;67(1):23-31. [PubMed: 14741321]

Green MF, Bracha HS, Satz P, Christenson CD. Preliminary evidence for an association between minor physical anomalies and second trimester neurodevelopment in schizophrenia. Psychiatry Res 1994b; 53(2):119-127. [PubMed: 7824672]

Green MF, Satz P, Christenson CD. Minor physical anomalies in schizophrenia patients, bipolar patients, and their siblings. Schizophr. Bull 1994a;20(3):433-440. [PubMed: 7973464]

Green MF, Satz P, Gaier DJ, Ganzell S, Kharabi F. Minor physical anomalies in schizophrenia. Schizophr. Bull 1989;15(1):91-99. [PubMed: 2717891]

Griffiths TD, Sigmundsson T, Takei N, Frangou S, Birkett PB, Sharma T, Reveley AM, Murray RM. Minor physical anomalies in familial and sporadic schizophrenia: the Maudsley family study. J. Neurol. Neurosurg. Psychiatry 1998;64(1):56-60. [PubMed: 9436728]

Gualtieri CT, Adams A, Shen CD, Loiselle D. Minor physical anomalies in alcoholic and schizophrenic adults and hyperactive and autistic children. Am. J. Psychiatry 1982;139(5):640-643. [PubMed: 7072852]

Guy JD, Majorski LV, Wallace CJ, Guy MP. The incidence of minor physical anomalies in adult male schizophrenics. Schizophr. Bull 1983;9(4):571-582. [PubMed: 6658393]

Harrison PJ. The neuropathology of schizophrenia. A critical review of the data and their interpretation. Brain 1999;122(4):593-624. [PubMed: 10219775]

Hata K, Iida J, Iwasaka H, Negoro H, Kishimoto T. Association between minor physical anomalies and leteral ventricular enlargement in childhood and adolescent onset schizophrenia. Acta Psychiatr. Scand 2003b;108(2):147-151. [PubMed: 12823172]

Hata K, Iida J, Iwasaka H, Negoro HI, Ueda F, Kishimoto T. Minor physical anomalies in childhood and adolescent onset schizophrenia. Psychiatry Clin. Neurosci 2003a;57(1):17-21. [PubMed: 12519450]

Hedges, LV.; Olkin, I. Statistical Methods for Meta-Analysis. Orlando: Academic Press, Inc.; 1985.

Hennessy RJ, Lane A, Kinsella A, Larkin C, O'Callaghan E, Waddington JL. 3D morphometrics of craniofacial dysmorphology reveals sex-specific asymmetries in schizophrenia. Schizophr. Res 2004;67(2-3):261-268. [PubMed: 14984886]

Hoyme HE. Minor anomalies: diagnostic clues to aberrant human morphogenesis. Genetica 1993;89(13):307-315.

Ismail B, Cantor-Graae E, McNeil TF. Minor physical anomalies in schizophrenic patients and their siblings. Am. J. Psychiatry 1998;155(12):1695-1702. [PubMed: 9842778]

Ismail B, Cantor-Graae E, McNeil TF. Minor physical anomalies in schizophrenia: cogitive, neurological and other clinical correlates. J. Psychiatr. Res 2000;34(1):45-56. [PubMed: 10696832]

Jones, KL. Smith's Recognizable Patterns of Human Malformation. Philadelphia: W.B. Saunders Company; 1997.

Joo EJ, Jeong SH, Ahn YN, Lee KY, Yoon SC, Kim EJ, Kim SU, Cho SC, Kim YS. No association found between $158 \mathrm{Val} / \mathrm{Met}$ polymorphism of the COMT gene and schizophrenia with minor physical anomalies. Psychiatry Res 2005;136(2-3):83-91. [PubMed: 16109444]

Kelly BD, Lane A, Agartz I, Henriksson KM, McNeil TF. Craniofacial dysmorphology in Swedish schizophrenia patients. Acta Psychiatr. Scand 2005;111(3):202-207. [PubMed: 15701104]

Kline, RB. Beyond Significance Testing: Reforming Data Analysis Methods in Behavioral Research. Washington, DC: American Psychological Association; 2004. 
Kravariti, E.; Dazzan, P.; Fearon, P.; Murray, RM. Can one identify preschizophrenic children?. In: Keshavan, MS.; Kennedy, JL.; Murray, RM., editors. Neurodevelopment and Schizophrenia. Cambridge: Cambridge University Press; 2004. p. 415-431.

Krause JP, Kauffman JM. Minor physical anomalies in exceptional children: a review and critique of research. J. Abnorm. Child Psychol 1982;10(2):247-264. [PubMed: 7108065]

Lal R, Sharma S. Minor physical anomalies in schizophrenia. Indian J. Psychiatry 1987;29(2):119-122.

Lane A, Kinsella A, Murphy P, Byrne M, Keenan J, Colgan K, Cassidy B, Sheppard N, Horgan R, Waddington JL, Larkin C, O'Callaghan E. The anthropometric assessment of dysmorphic features in schizophrenia as an index of its developmental origins. Psychol. Med 1997;27(5):1155-1164. [PubMed: 9300519]

Lawrie SM, Byrne M, Miller P, Hodges A, Clafferty R, Owens DC, Johnstone EC. Neurodevelopmental indices and the development of psychotic symptoms in subjects at high risk of schizophrenia. Br. J. Psychiatry 2001;178(6):524-530. [PubMed: 11388968]

Le Douarin, NM.; Kalcheim, C. The Neural Crest. Cambridge: Cambridge University Press; 1999.

Lloyd T, Doody G, Brewin J, Park B, Jones P. Minor physical anomalies in schizophrenia: is age a confounding factor? Schizophr. Res 2003;61(1):67-73. [PubMed: 12648737]

Lohr JB, Alder M, Flynn K, Harris MJ, McAdams LA. Minor physical anomalies in older patients with late-onset schizophrenia, early-onset schizophrenia, depression, and Alzheimer's disease. Am. J. Geriatr. Psychiatry 1997;5(4):318-323. [PubMed: 9363288]

Lohr JB, Flynn K. Minor physical anomalies in schizophrenia and mood disorders. Schizophr. Bull 1993;19(3):551-556. [PubMed: 8235457]

Marcus J, Hans SL, Byhouwer B, Norem J. Relationships among neurological functioning, intelligence quotients, and physical anomalies. Schizophr. Bull 1985;11(1):101-106. [PubMed: 3983568]

Marenco S, Weinberger DR. The neurodevelopmental hypothesis of schizophrenia: following a trail of evidence from the cradle to grave. Dev. Psychopathol 2000;12(3):501-527. [PubMed: 11014750]

McGrath JJ, El-Saadi O, Grim V, Cardy S, Chapple B, Chant D, Lieberman D, Mowry B. Minor physical anomalies and quantitative measures of the head and face in patients with psychosis. Arch. Gen. Psychiatry 2002;59(5):458-464. [PubMed: 11982450]

McGrath JJ, Feron FP, Burne THJ, Mackay-Sim A, Eyles DW. The neurodevelopmental hypothesis of schizophrenia: a review of recent developments. Ann. Med 2003;35(2):86-93. [PubMed: 12795338]

McGrath JJ, van Os J, Jones PB, Harvey I, Murray RM. Minor physical anomalies in psychosis: associations with clinical and putative aetiological variables. Schizophr. Res 1995;18(1):9-20. [PubMed: 8929756]

McNeil TF, Blennow G, Lundberg L. Congenital malformations and structural developmental anomalies in groups at high risk for psychosis. Am. J. Psychiatry 1992;149(1):57-61. [PubMed: 1728186]

McNeil TF, Cantor-Graae E. Does preexisting abnormality cause labor-delivery complications in fetuses who will develop schizophrenia? Schizophr. Bull 1999;25(3):425-435. [PubMed: 10478778]

McNeil TF, Cantor-Graae E. Minor physical anomalies and obstetric complications in schizophrenia. Aust. N. Z. J. Psychiatry 2000;34:S65-S73. [PubMed: 11129318]

McNeil TF, Cantor-Graae E, Ismail B. Obstetric complications and congenital malformation in schizophrenia. Brain Res. Brain Res. Rev 2000;31(2-3):166-178. [PubMed: 10719145]

Murphy K, Owen MJ. Minor physical anomalies and their relationship to the aetiology of schizophrenia. Br. J. Psychiatry 1996;168(2):139-142. [PubMed: 8837901]

Murray RM, O'Callaghan E, Castle DJ, Lewis SW. A neurodevelopmental approach to the classification of schizophrenia. Schizophr. Bull 1992;18(2):319-332. [PubMed: 1377834]

Nizamie SH, Nizamie A, Sangma MW, Sharma PL. Soft neurological signs and minor physical anomalies in schizophrenia. Indian J. Psychiatry 1989;31(3):230-237.

O'Callaghan E, Buckley P, Madigan C, Redmond O, Stack JP, Kinsella A, Larkin C, Ennis JT, Waddington JL. The relationship of minor physical anomalies and other putative indices of developmental disturbance in schizophrenia to abnormalities of cerebral structure on magnetic resonance imaging. Biol. Psychiatry 1995;38(8):516-524. [PubMed: 8562663] 
O'Callaghan E, Larkin C, Kinsella A, Waddington JL. Familial, obstetric, and other clinical correlates of minor physical anomalies in schizophrenia. Am. J. Psychiatry 1991;148(4):479-483. [PubMed: 2006694]

Ponnudurai R. A study of some somatic traits in schizophrenia. Indian J. Psychiatry 1986;28(3):249-251.

Puri BK, El-Dosoky A, Cheema S, Lekh SK, Hall AD, Mortimer AM. Parietal scalp hair whorl patterns in schizophrenia. Biol. Psychiatry 1995;37(4):278-279. [PubMed: 7711167]

Roberts GW, Colter N, Lofthouse R, Johnstone EC, Crow TJ. Is there gliosis in schizophrenia? Investigation of the temporal lobe. Biol. Psychiatry 1987;22(12):1459-1468. [PubMed: 3315013]

Rosenthal R. The 'file drawer' problem and tolerance for null results. Psychol. Bull 1979;86(3):638-641.

Schiffman J, Ekstrom M, LaBrie J, Schulsinger F, Sorenson H, Mednick S. Minor physical anomalies and schizophrenia spectrum disorders: a prospective investigation. Am. J. Psychiatry 2002;159(2): 238-243. [PubMed: 11823265]

Scutt LE, Chow EWC, Weksberg R, Honer WG, Bassett AS. Patterns of dysmorphic features in schizophrenia. Am. J. Med. Genet 2001;105(8):713-723. [PubMed: 11803519]

Sivkov ST, Akabaliev VH. Minor physical anomalies in schizophrenic patients and normal controls. Psychiatry 2003;66(3):222-233. [PubMed: 14587359]

Sivkov ST, Akabaliev VH. Discriminating value of total minor anomaly score on the Waldrop physical anomaly scale between schizophrenia patients and normal control subjects. Schizophr. Bull 2004;30 (2):361-366. [PubMed: 15279053]

Sutton, AJ.; Abrams, KR.; Jones, DR.; Sheldon, TA.; Song, F. Methods for Meta-Analysis in Medical Research. Chichester: John Wiley \& Sons, Ltd; 2000.

Tarrant CJ, Jones PB. Precursors to schizophrenia: do biological markers have specificity. Can. J. Psychiatry 1999;44(4):335-349. [PubMed: 10332574]

Thompson SG, Sharp SJ. Explaining heterogeneity in meta-analysis: a comparison of methods. Stat. Med 1999;18(20):2693-2708. [PubMed: 10521860]

Trixler M, Tényi T, Csábi G, Szabó R. Minor physical anomalies in schizophrenia and bipolar affective disorder. Schizophr. Res 2001;52(3):195-201. [PubMed: 11705713]

Trixler M, Tényi T, Csábi G, Szabó G, Méhes K. Informative morphogenetic variants in patients with schizophrenia and alcohol-dependant patients: beyond the Waldrop scale. Am. J. Psychiatry 1997;154(5):691-693. [PubMed: 9137130]

Waddington JL, Lane A, Scully P, Meagher D, Quinn J, Larkin C, O'Callaghan E. Early cerebrocraniofacial dysmorphogenesis in schizophrenia: a lifetime trajectory model from neurodevelopmental basis to 'neuroprogressive' process. J. Psychiatr. Res 1999;33(6):477-489. [PubMed: 10628523]

Waddington JL, O'Callaghan E, Buckley P, Madigan C, Redmond O, Stack JP, Kinsella A, Larkin C, Ennis JT. Tardive dyskinesia in schizophrenia relationship to minor physical anomalies, frontal lobe dysfunction and cerebral structure on magnetic resonance imaging. Br. J. Psychiatry 1995; 167(1): 41-44. [PubMed: 7551606]

Waldrop, MF.; Halverson, CF. Minor physical anomalies and hyperactive behavior in children. In: Hellmuth, J., editor. Exceptional Infant: Studies in Abnormalities. New York: Brunner/Mazel; 1971. p. 343-380.

Waldrop MF, Pedersen FA, Bell RQ. Minor physical anomalies and behavior in preschool children. Child Dev 1968;39(2):391-400. [PubMed: 4172079]

Weinberger DR. Implications of normal brain development for the pathogenesis of schizophrenia. Arch. Gen. Psychiatry 1987;44(7):660-669. [PubMed: 3606332]

Weinstein DD, Diforio D, Schiffman J, Walker E, Bonsall R. Minor physical anomalies, dermatoglyphic asymmetries, and cortisol levels in adolescents with schizotypal personality disorder. Am. J. Psychiatry 1999;156(4):617-623. [PubMed: 10200743]

Woods BT. Is schizophrenia a progressive neurodevelopmental disorder? Toward a unitary pathogenetic mechanism. Am. J. Psychiatry 1998;155(12):1661-1670. [PubMed: 9842773] 


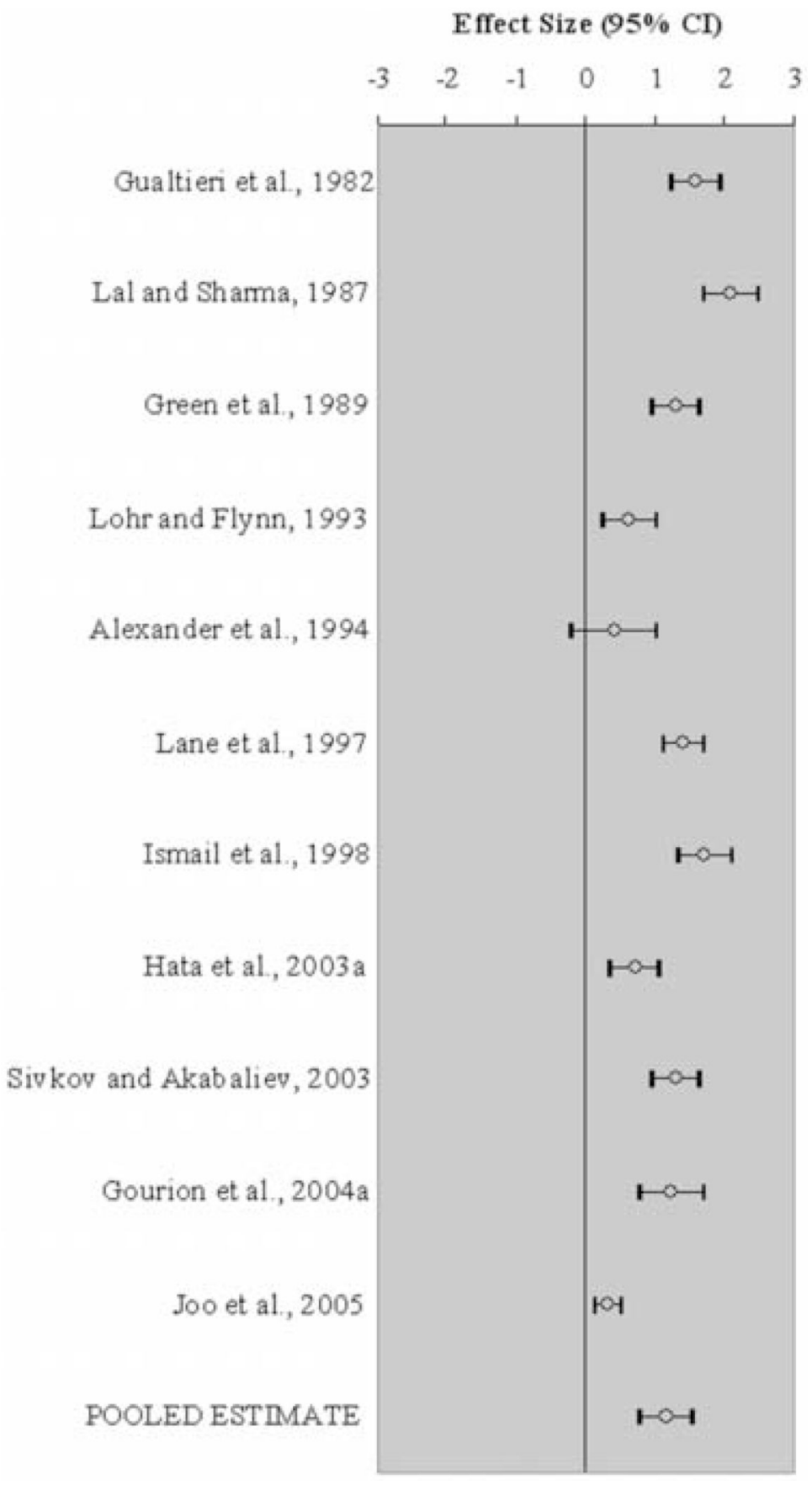

Fig. 1.

Effect sizes with $95 \%$ confidence intervals for each of the 11 studies (ordered by year of publication) that provided mean total MPA scores and the pooled effect size estimate (at the bottom of the figure). Point estimates to the right of the zero baseline indicate increased total MPA scores in schizophrenic individuals compared to controls. 


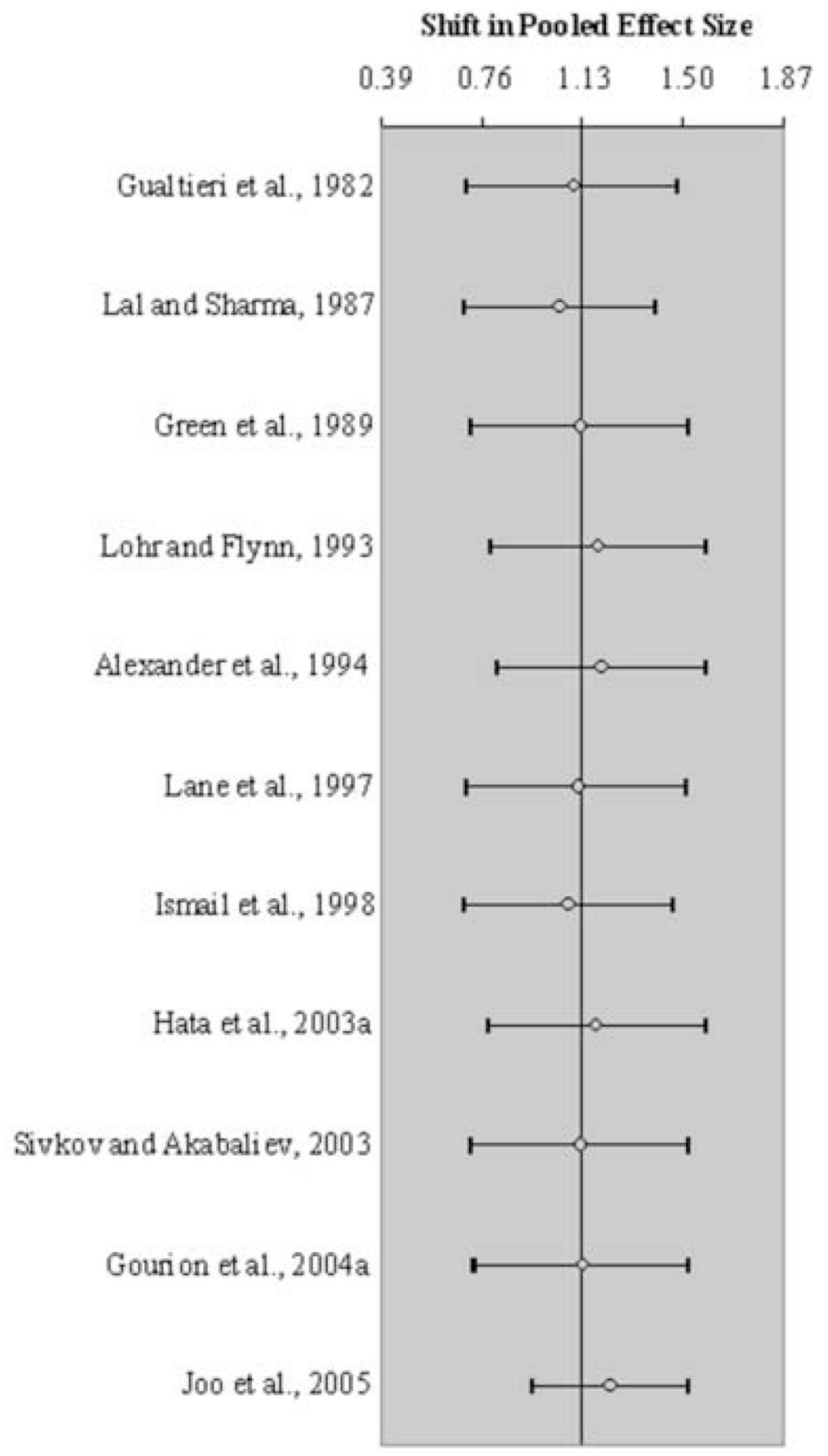

Fig. 2.

Sensitivity analysis demonstrating the effect of deleting any single study on the estimated pooled effect size (mean total MPA scores). The centrally located baseline $(+1.13)$ represents the original pooled effect size based on all 11 studies. The upper and lower bounds $(+1.50$ and +0.76 , respectively) represent the $95 \%$ confidence intervals of the original pooled estimate. As each study along the vertical axis is removed sequentially, the pooled effect size is recalculated for the remaining ten studies. These recalculated pooled effect sizes along with their $95 \%$ confidence intervals are depicted relative to the original pooled effect size estimate. The impact of a given study is illustrated graphically as a shift from the baseline; positive shifts (to the 
right of the baseline) indicate that the pooled estimated increased following removal of a given study. 


\section{Pooled Odds Ratio $(95 \% \mathrm{Cl})$}

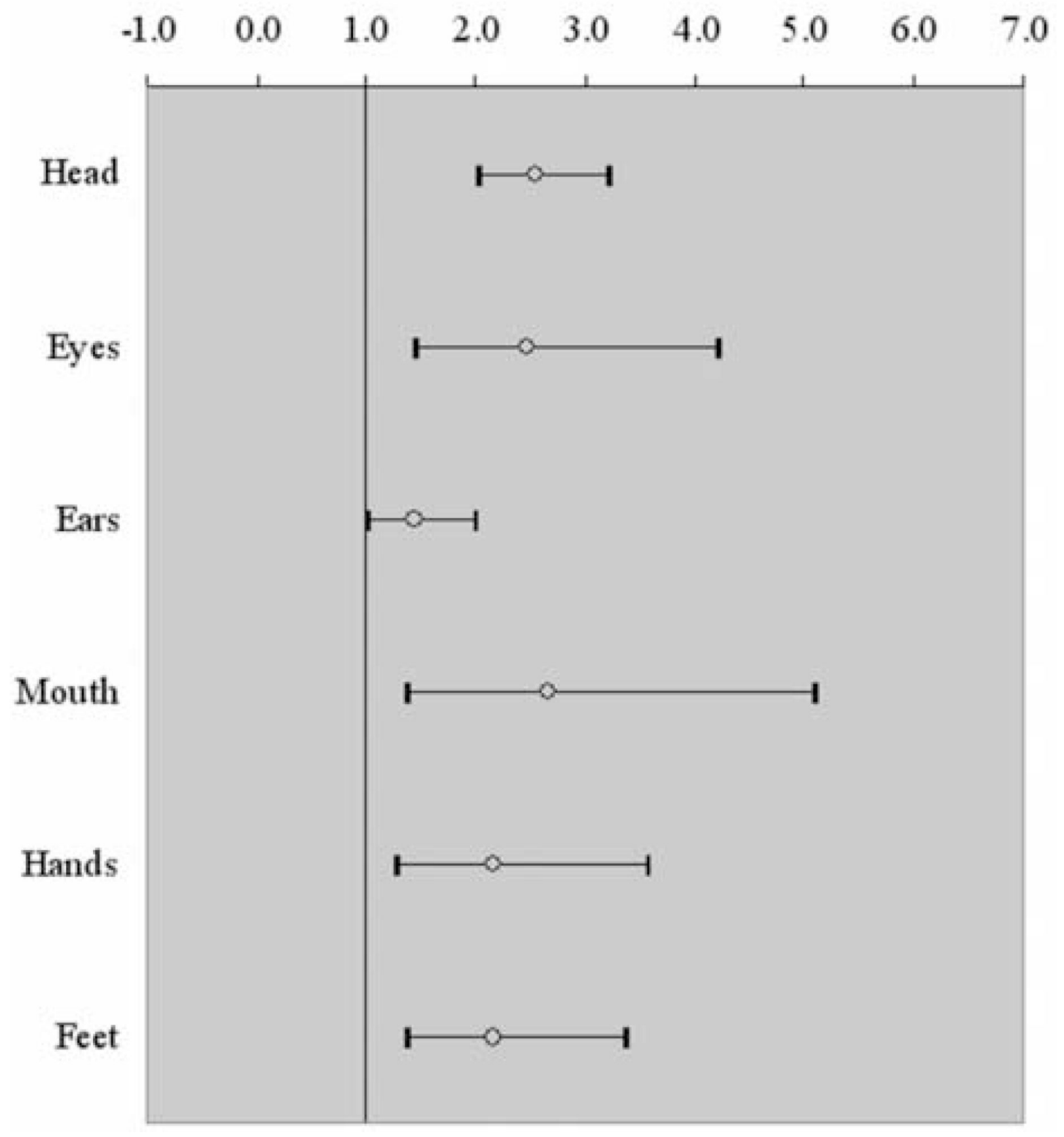

Fig. 3.

Pooled effect sizes (odds ratios) and their 95\% confidence intervals for MPAs across various anatomical regions. Point estimates to the right of the baseline $(O R=1)$ indicate increased MPA scores for a given region in schizophrenic individuals compared to controls. 


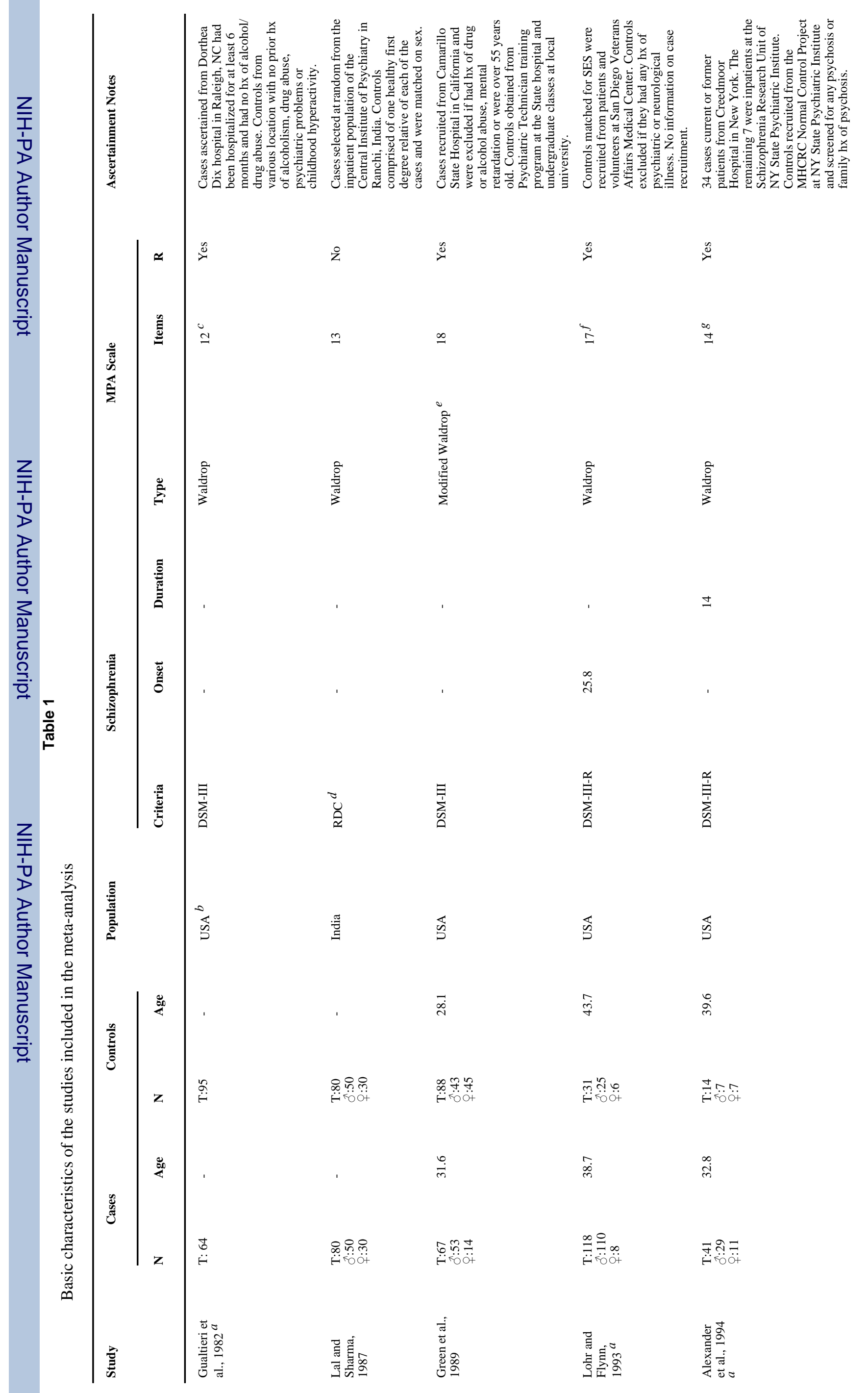




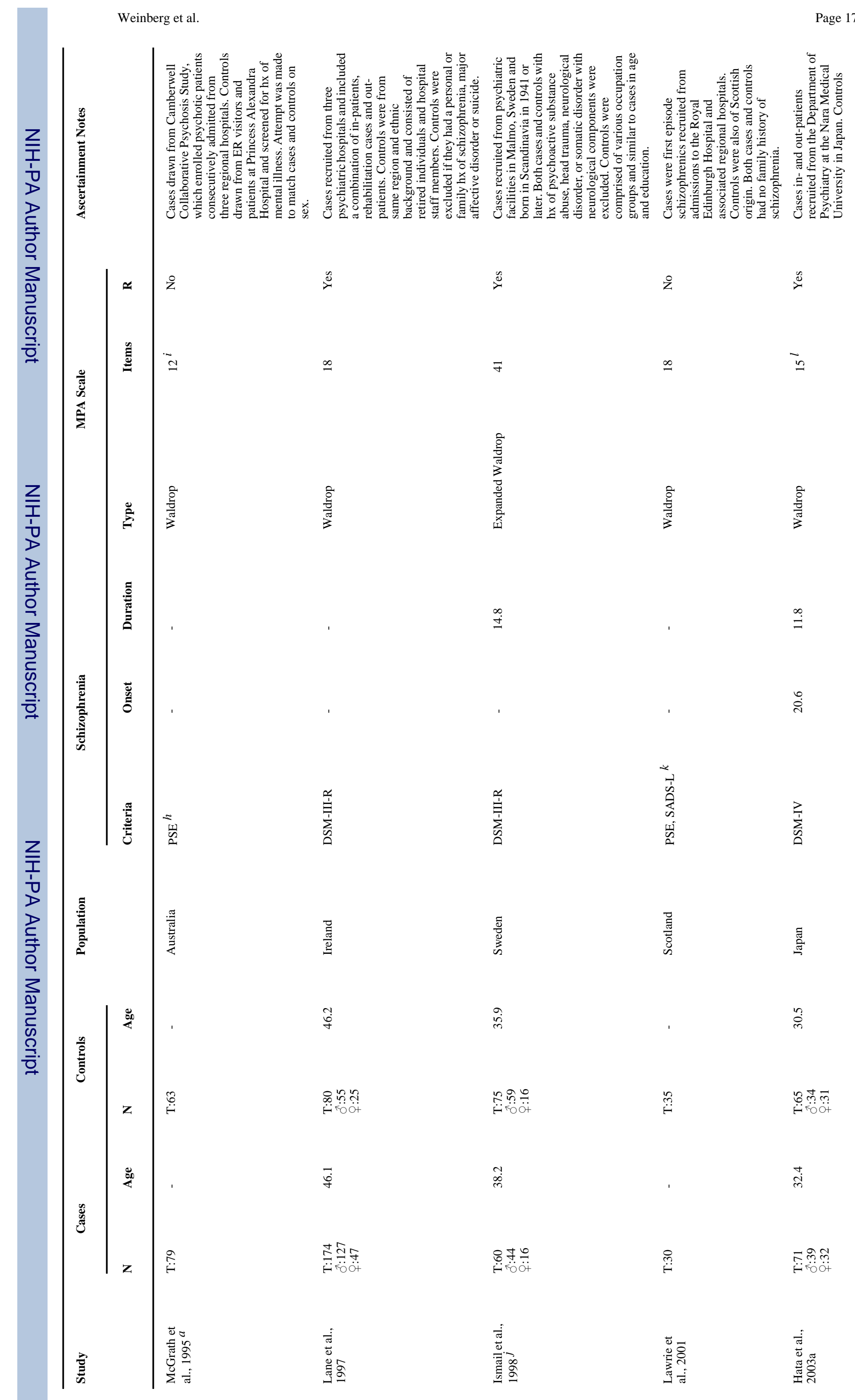




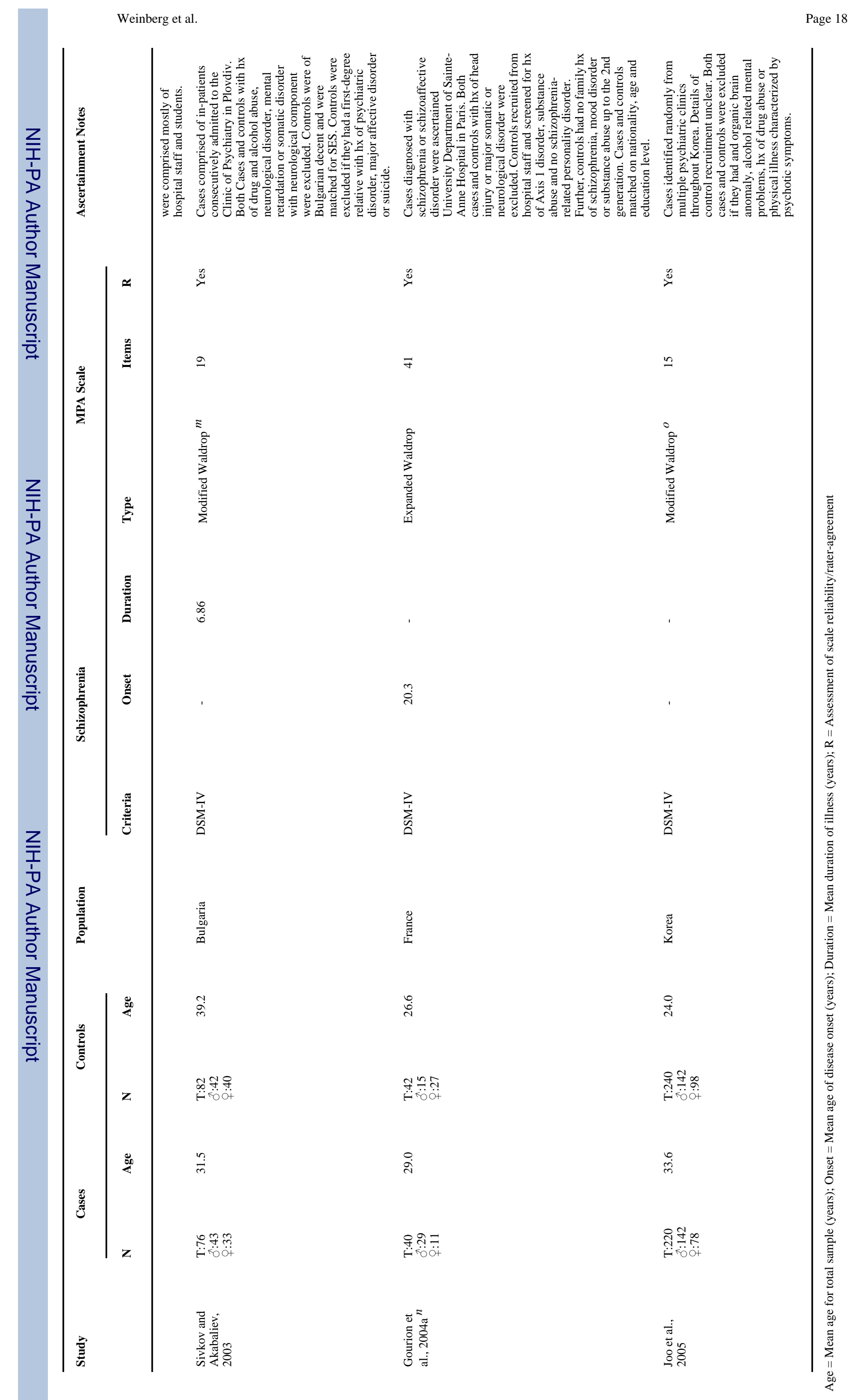


Table 2

Basis for exclusion of relevant studies identified from literature search

\begin{tabular}{|c|c|}
\hline Reason for exclusion & Studies $a$ \\
\hline Control subjects not included & $\begin{array}{l}\text { Guy et al., 1983; Green et al., 1987; 1994a; Nizamie et al., 1989; O' Callaghan et al., 1991; 1995; } \\
\text { Waddington et al., 1995; McNeil and Cantor-Graae, 1999; Scutt et al., 2001; Hata et al., 2003b }\end{array}$ \\
\hline $\begin{array}{l}\text { Mean MPA scores and/or raw MPA } \\
\text { frequencies not available for one or both } \\
\text { groups }\end{array}$ & $\begin{array}{l}\text { McNeil et al., 1992; Buckley et al., 1994; Trixler et al., 1997; 2001; Griffiths et al., 1998; Ismail et } \\
\text { al., 2000; Akabaliev et al., 2001; Schiffman et al., 2002; Elizarrarás-Rivas et al., 2003; Lloyd et al., } \\
\text { 2003; Edgar et al., } 2006\end{array}$ \\
\hline Waldrop scale or variant not used & $\begin{array}{l}\text { Ponnudurai et al., 1986; McNeil et al., 1992; Puri et al., 1995; Trixler et al., 1997; 2001; Scutt et } \\
\text { al., 2001; McGrath et al., 2002; Lloyd et al., } 2003\end{array}$ \\
\hline $\begin{array}{l}\text { Samples potentially overlap with an } \\
\text { included study }\end{array}$ & $\begin{array}{l}\text { Green et al., 1994a; 1994b; O'Callaghan et al., 1995; Waddington et al., 1995; Lohr et al., 1997; } \\
\text { Akabaliev and Sivkov, 1998; 2003; Cantor-Graae et al., 1998; Ismail et al., 2000; Akabaliev et al., } \\
\text { 2001; Gourion et al., 2003; 2004b; Hata et al., 2003b; Sivkov and Akabaliev, } 2004\end{array}$ \\
\hline $\begin{array}{l}\text { Diagnosis of isolated schizophrenia } \\
\text { lacking in the case group }\end{array}$ & $\begin{array}{l}\text { Marcus et al., 1985; McNeil et al., 1992; Weinstein et al., 1999; Scutt et al., 2001; McGrath et al., } \\
\text { 2002; Schiffman et al., 2002; Lloyd et al., } 2003\end{array}$ \\
\hline Twin study & Cantor-Graae et al., 1994; McNeil and Cantor-Graae, 1999; McNeil et al., 2000 \\
\hline
\end{tabular}

${ }^{a}$ Studies may appear multiple times if more than one reason for their exclusion exists 


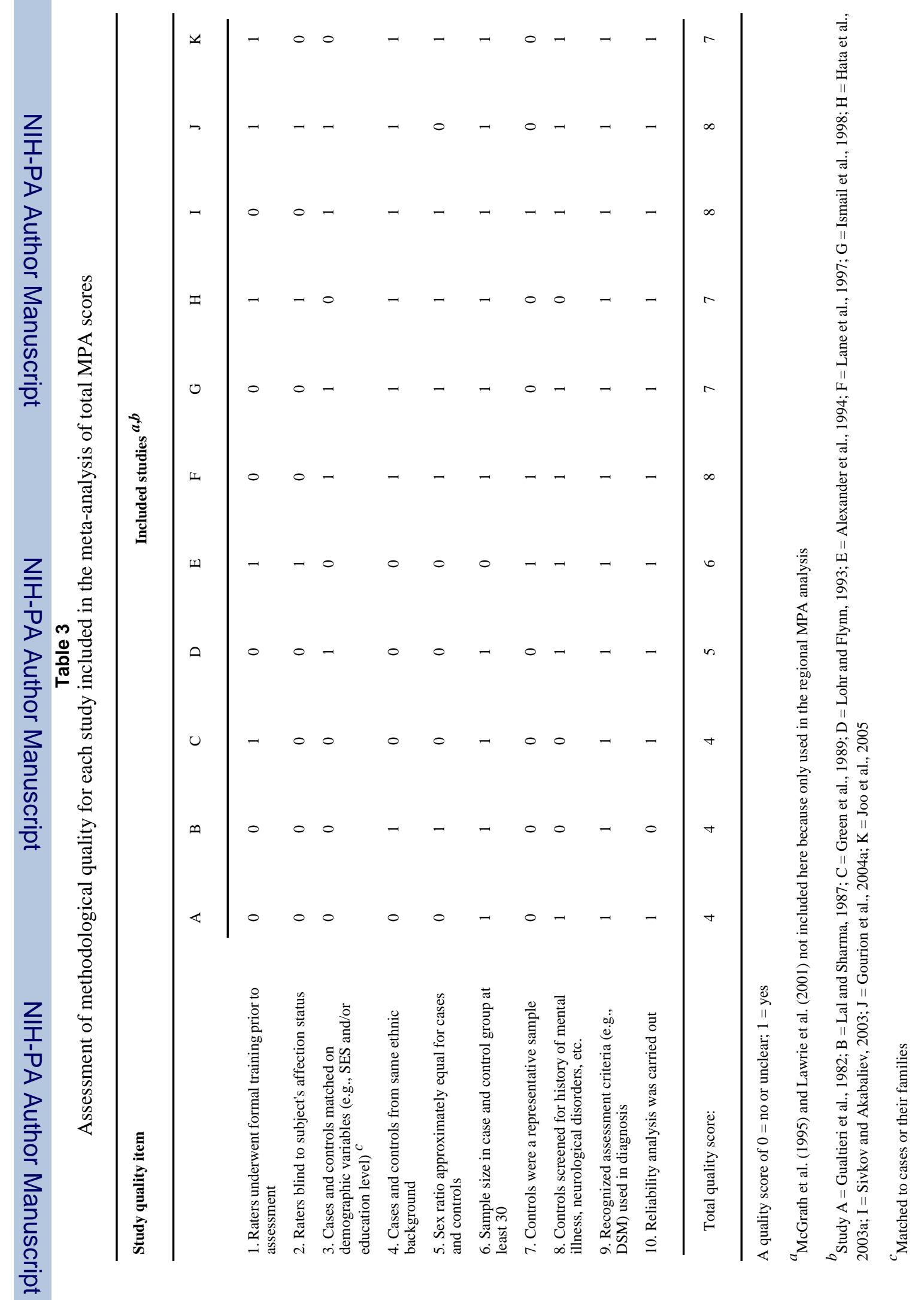




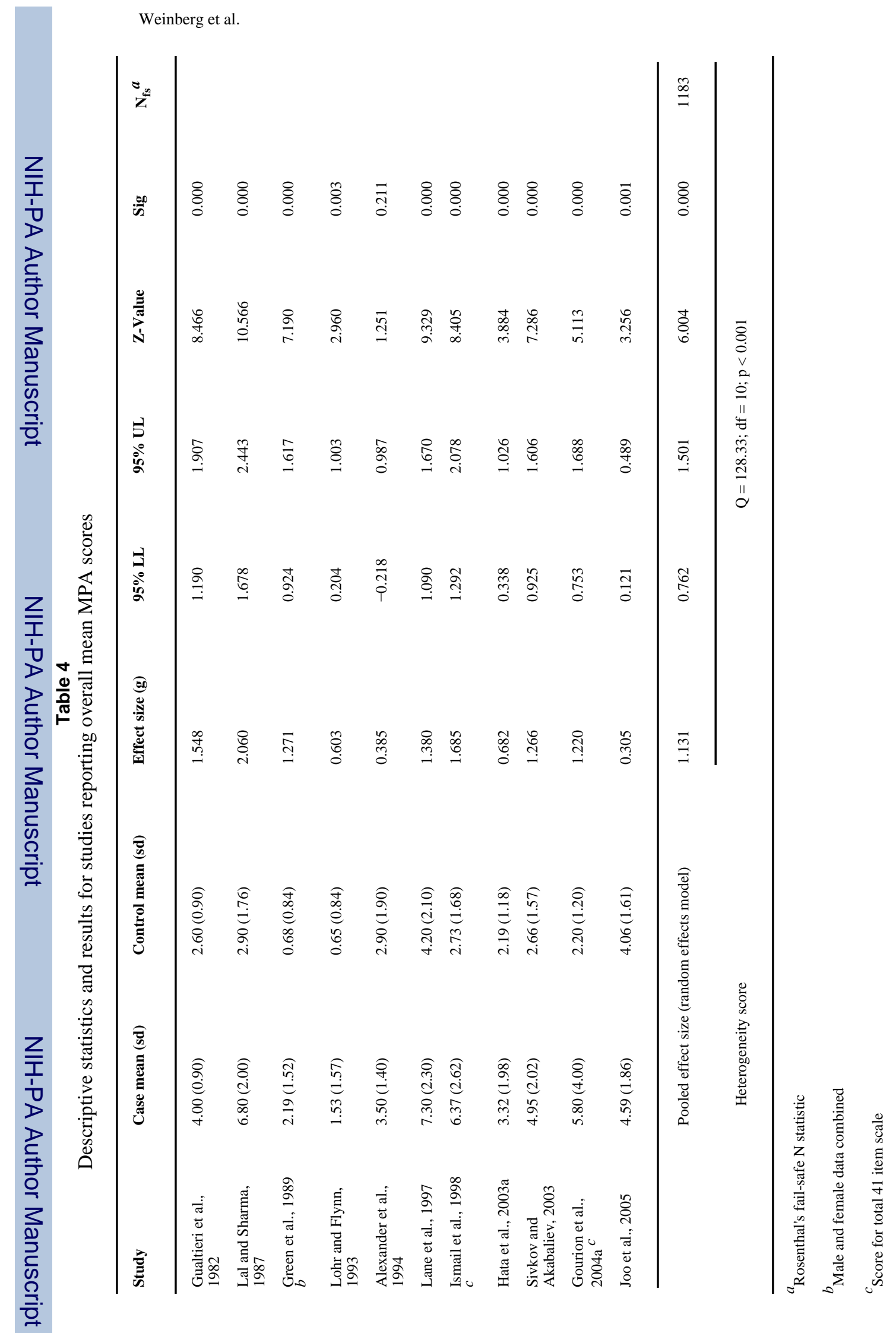

Page 22 


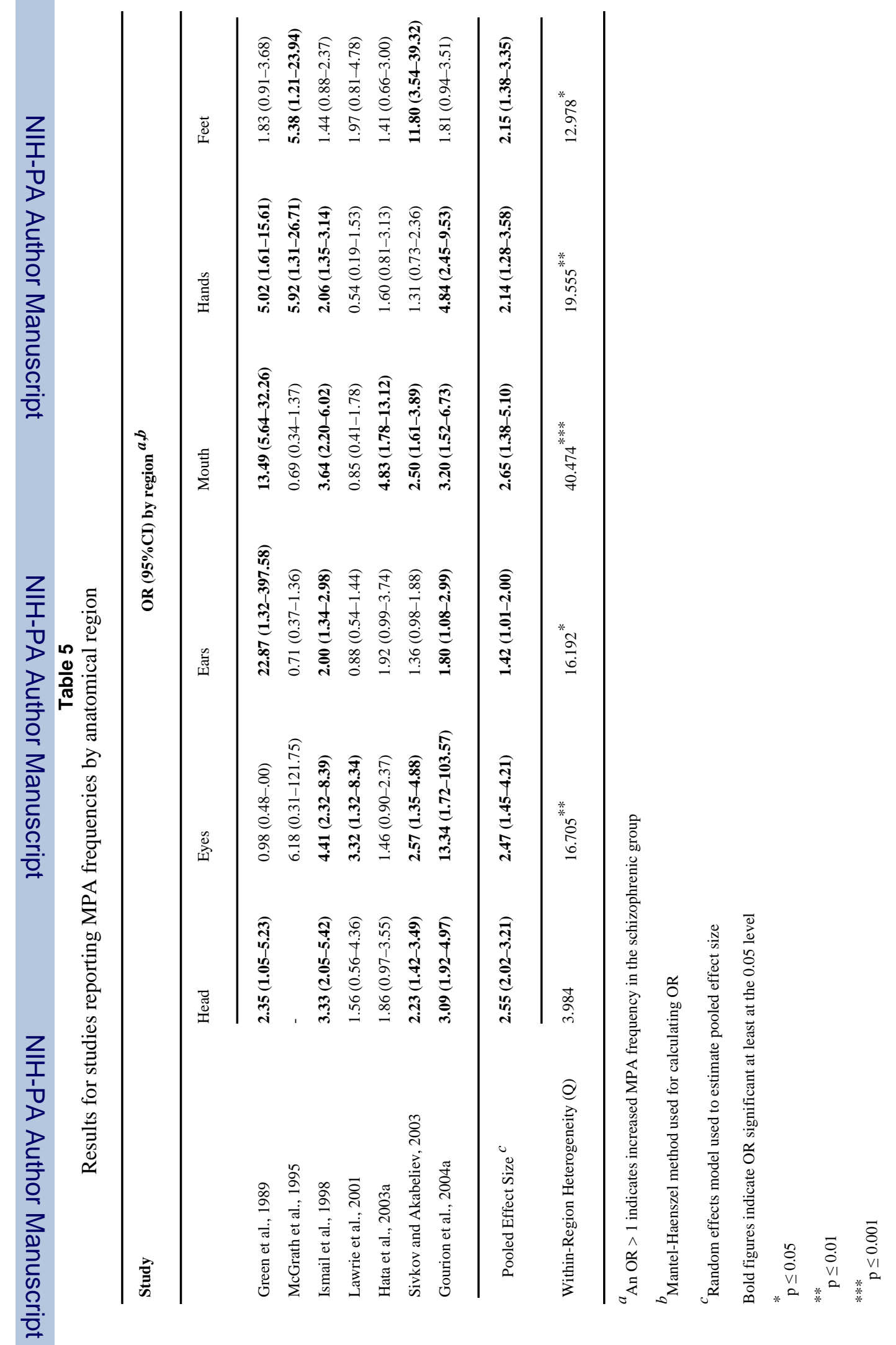

